\title{
العقوبة الجزائية الدولية المطبقة على الافراد في اطار المحكمة الجنائية الدولية
}

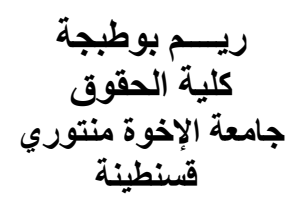

مقدمة:

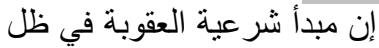

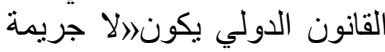

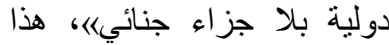
الجزاء يجد أساسه في مصادياد الداء القانون الدولي المختلفة سواء منها الاتفاقية أو العرفية، فإذا العاء

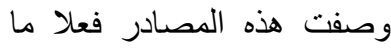
أنه جريمة دولية وخصته بجز اليهاء جنائي أي بعقاب داعله دوله دخل الفعل في نطاق القانون الدولي الجنائي وإذا لم تصفل بكونة الفنه

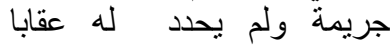
لمرتكبه خرج الفعل على نطاق لمان هذا القانون حتى ولو كان فئل فعلا غير مشروع مستوجب لقئ لقيام المسئولية الدولية الدنية.

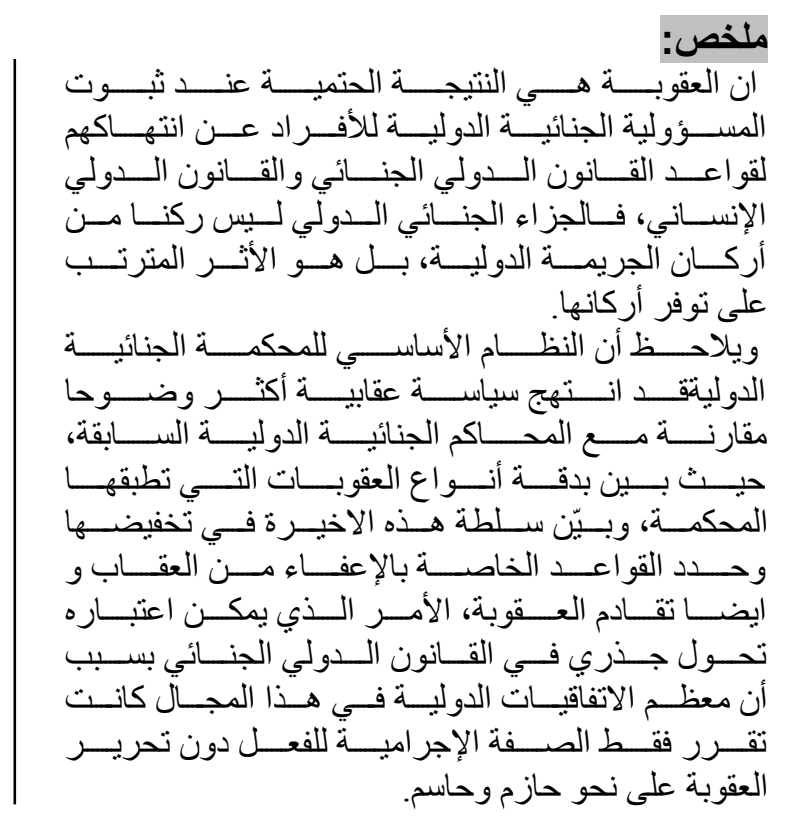

\section{Abstract :}

Punishment is the consequent result when the of individuals' responsibility of violation of the International Criminal Law and the International Humanitarian Law is proved, the international penal lawis not regarded as a pillar of international crime; but it is theresulted impact on its provided consequences.

And is noted that the basic system of the International CriminalCourt (Rome Statute of 1998) has followed a more explicit punitivepolicy in comparing it with the previous International CriminalCourts; where, it has shown exactly types of the sanctions the courtapplied, and has clarified the latter's authority in their reductionand has restricted the special rules for the exemption from punishmentand also the aging of the punishment, the matter which can beconsidered as a radical shift in the International Criminal Law forthe most International Conventions in this field were only decidingabout the criminal attribute of the act without editing punishment ina firm and decisive trend. 
ولم ينص القانون الدولي العرفي والاتفاقيات الدولية الخاصة بالقانون الدولي الإنساني على عقوبات

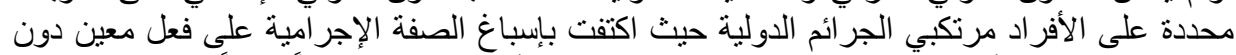

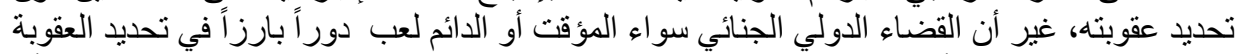

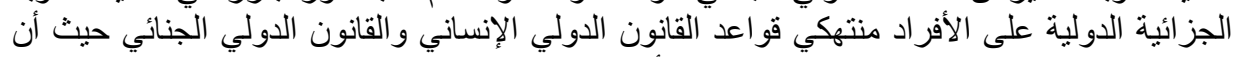

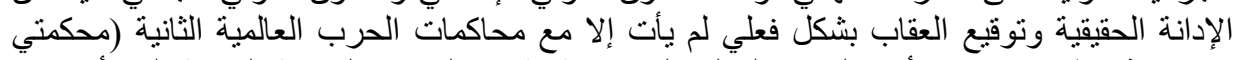

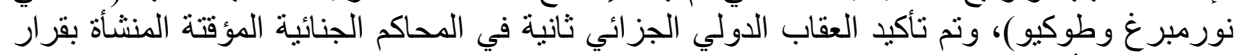

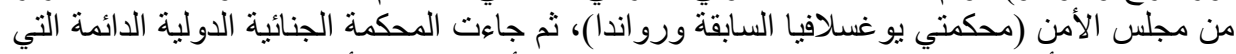

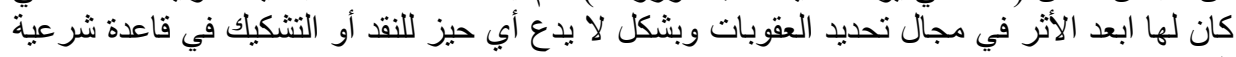

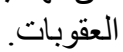

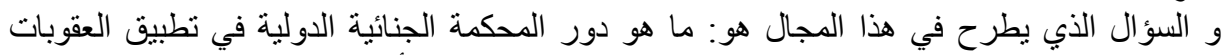

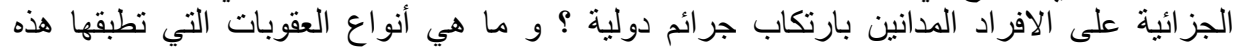

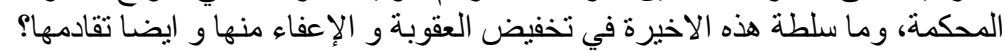

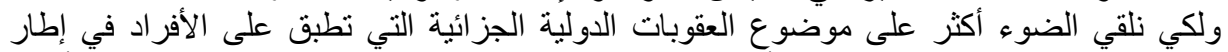

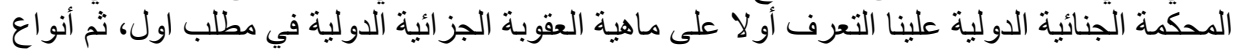

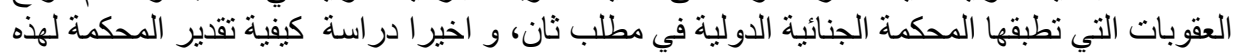

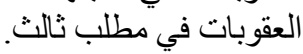

المطلب الاول: ماهية العقوبة الجزائية الدولية

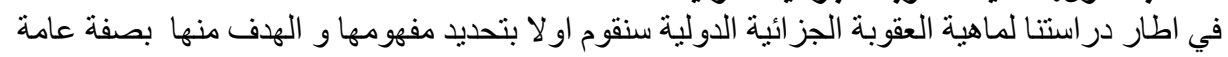

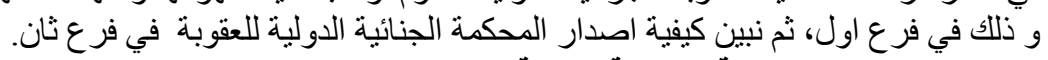

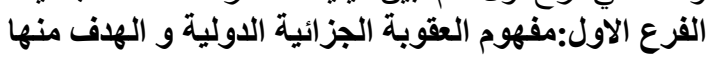

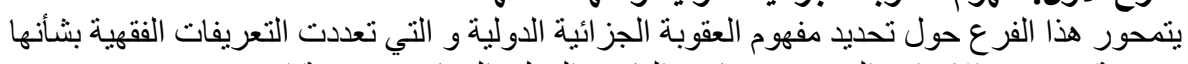

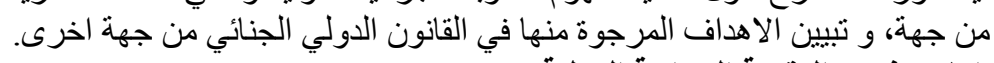

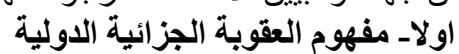

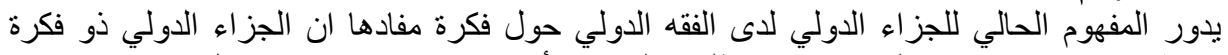

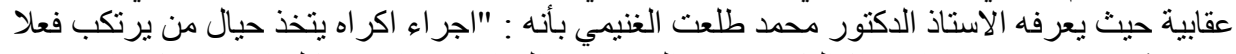

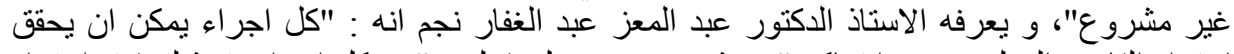

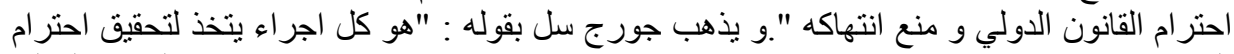

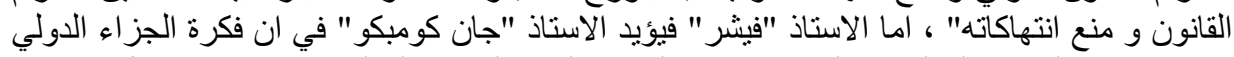

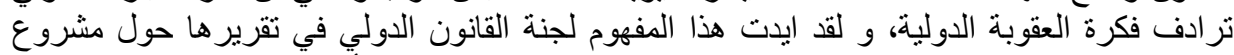

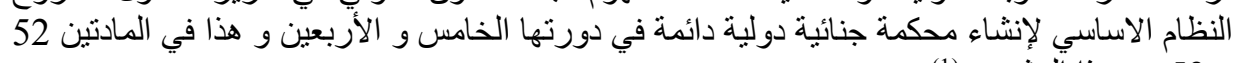

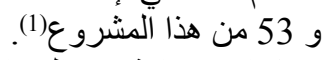

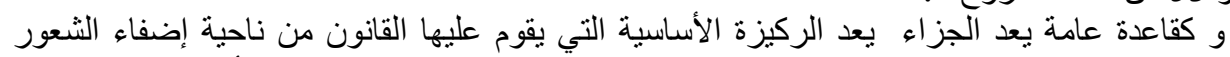

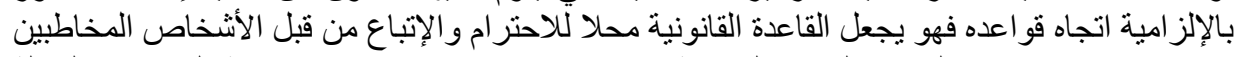

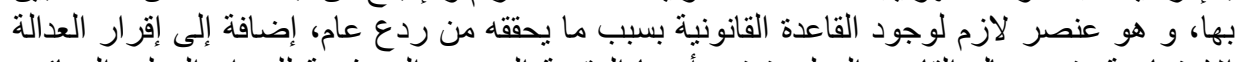

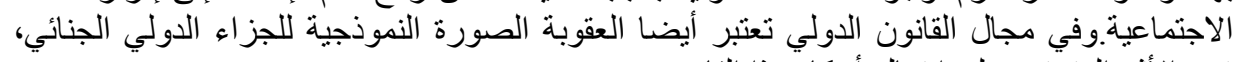

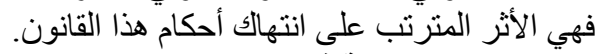

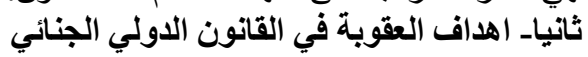

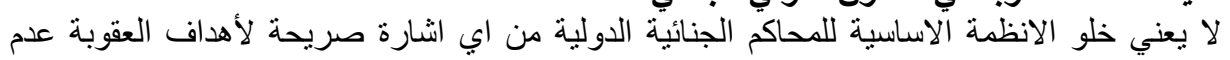

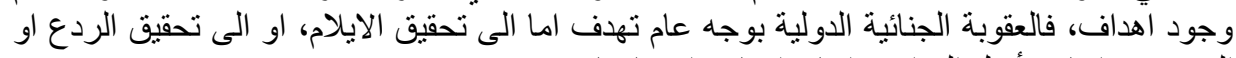

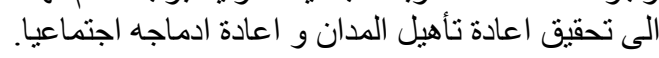

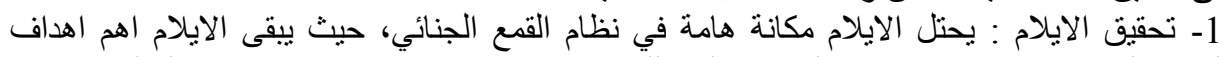

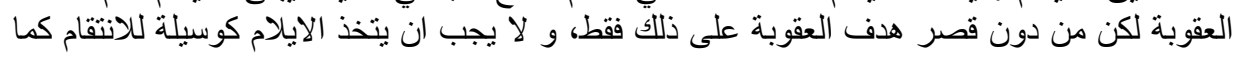




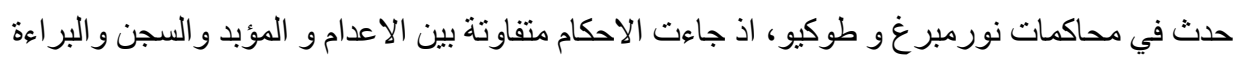

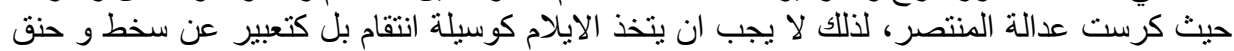

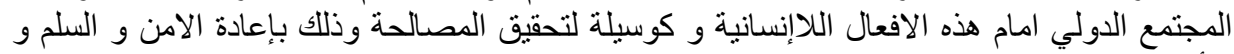

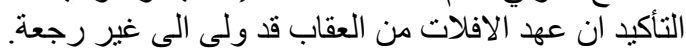

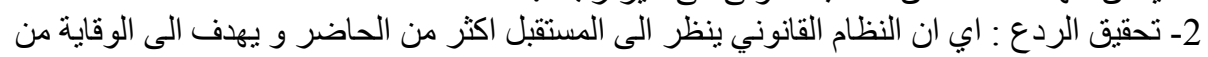

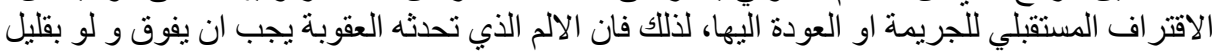

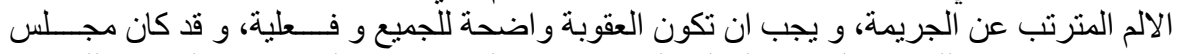

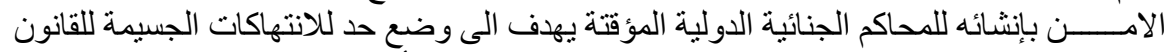

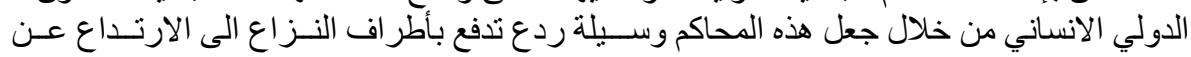

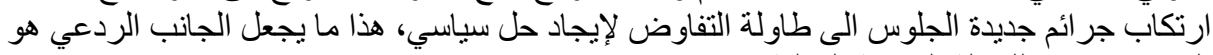
الدور الاساسي للعدالة الجنائية الدولية.

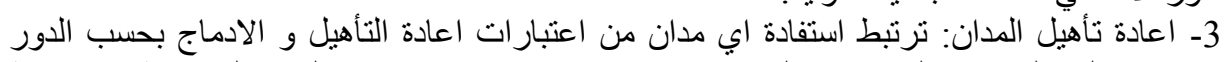

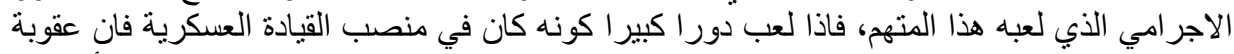

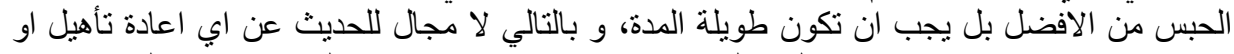

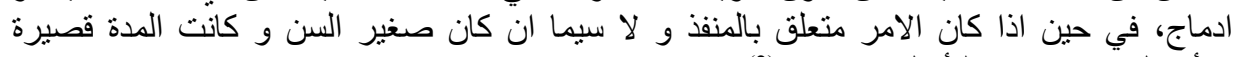

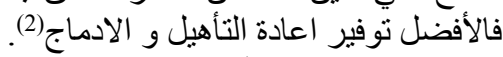

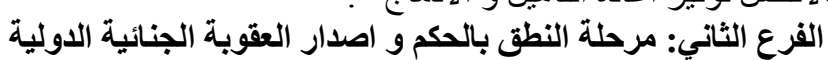

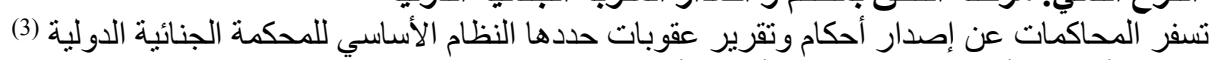

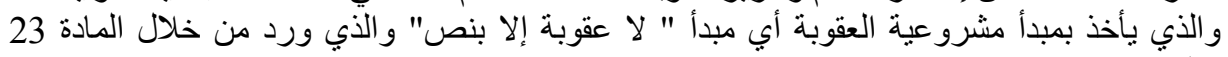

" لا يعاقب أب شخص أدانته الدحكمة إلا على وفق هذا النظام الأساسي ". "الحوله:

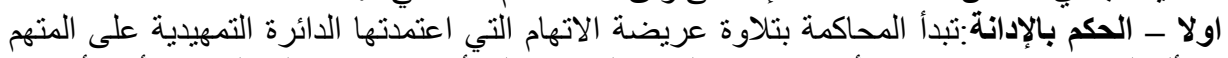

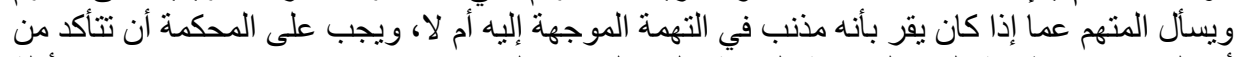

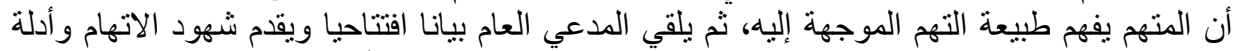

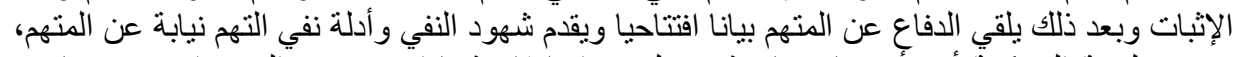

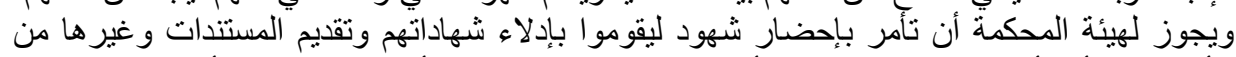

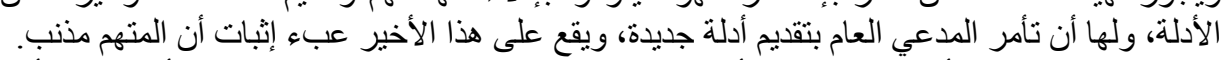

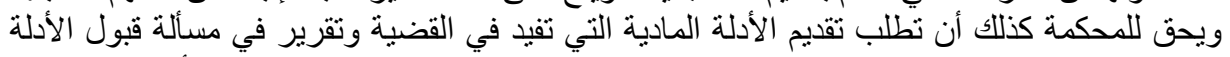

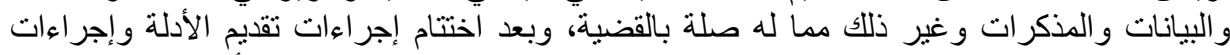

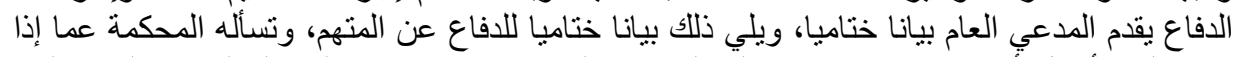

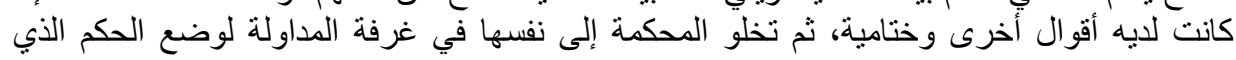
ستصدره

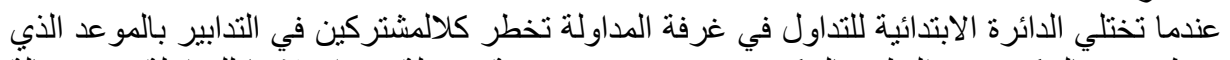

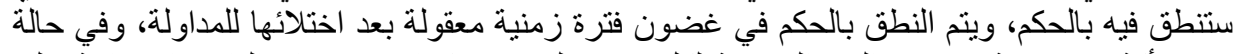

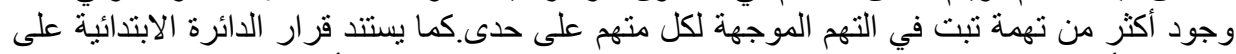

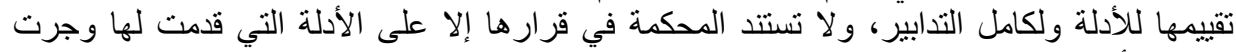

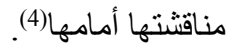

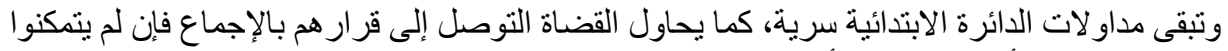

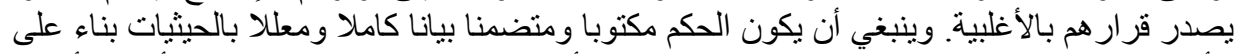

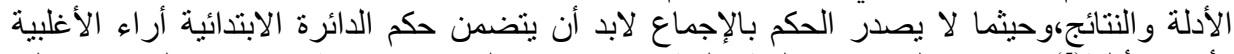

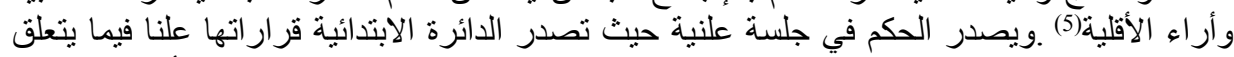

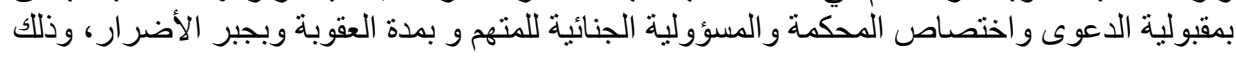


إن أمكن بحضور المتهم والمدعي العام والممتلين القانونيين للمجني عليهم المشتركين في التدابير، وممثلي الدول الذين انشتركو ا في التّابير.

ثانيا- الحكم بعدم العقاب

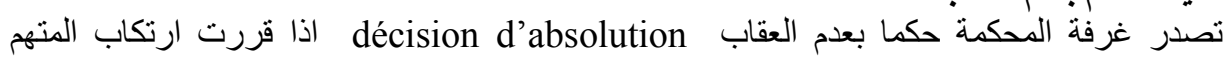

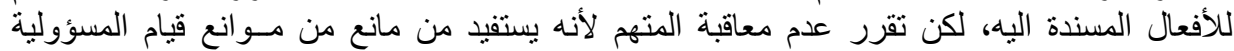

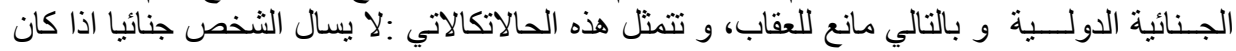

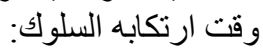

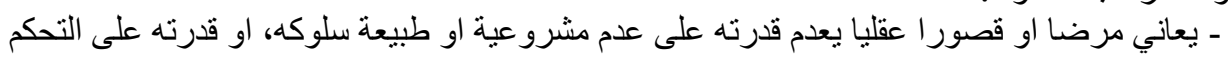

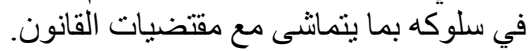

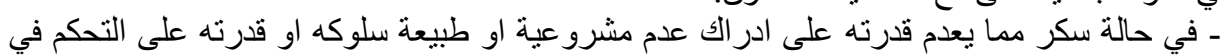

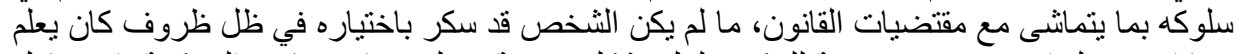

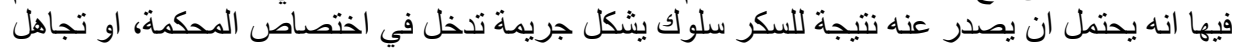

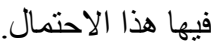

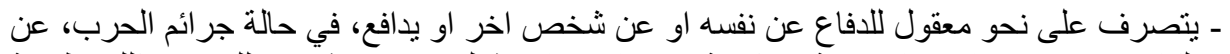

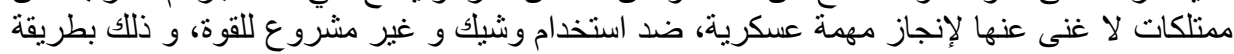

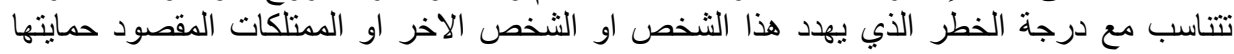

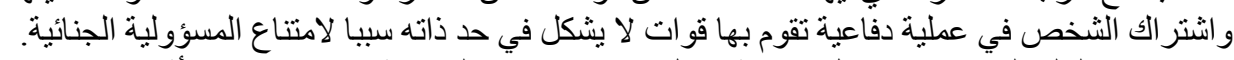

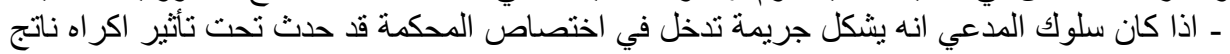
عن تهديد بالموت الوشيك او بحدوث ضرر بدني جسيم مستمر او وشيك ضد ذلك الك الثخص او شخص

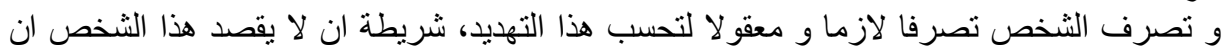

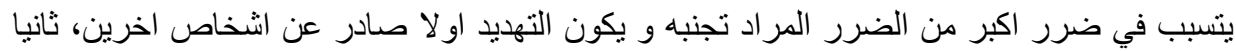

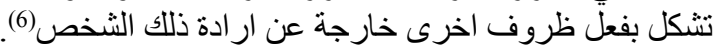

المطلب الثاني: أنواع العقوبات التي تطبقها المحكمة الجنائية الدولية على الأفراد

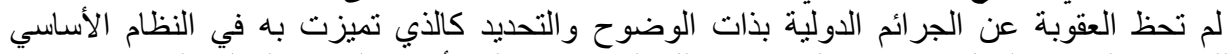

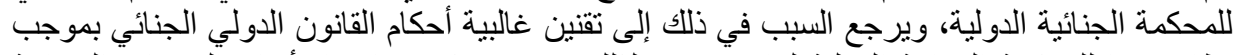

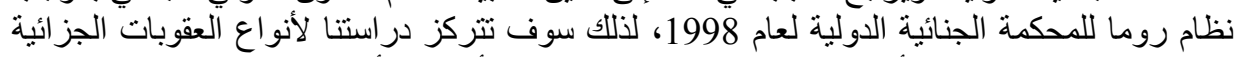

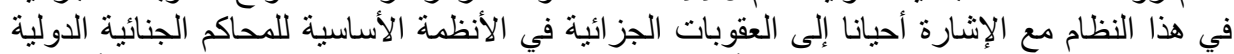

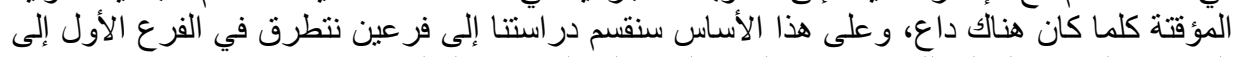

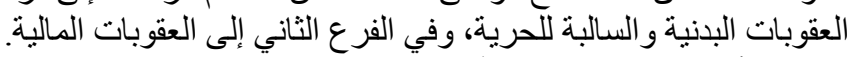

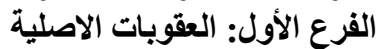

نتطرق في هذا الفرع إلى كيفية تطبيق القضاء الإبة الدولي الجنائي و بالأخص المحكمة الجنائية الدولية

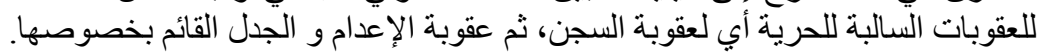

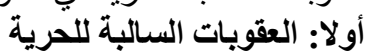

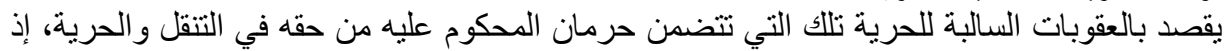

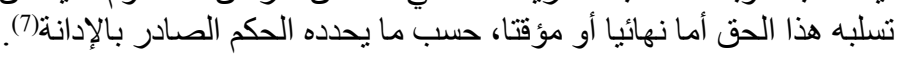

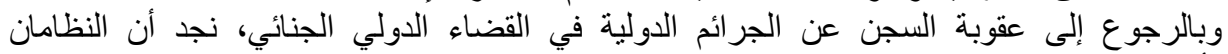

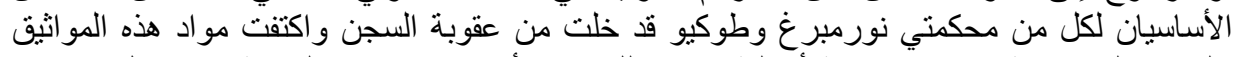

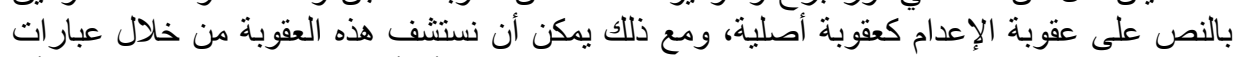

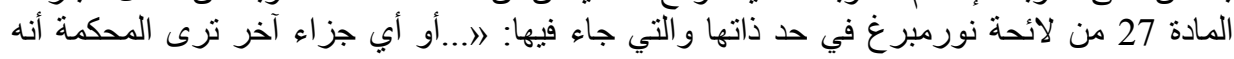


عادله، لذلك استعمل قضاة المحكمة سلطتهم التقديرية وأصدروا عقوبات بالسجن في كثير من الأحكام،

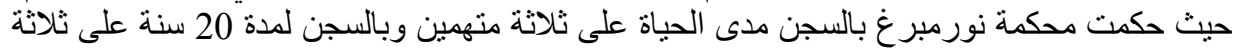

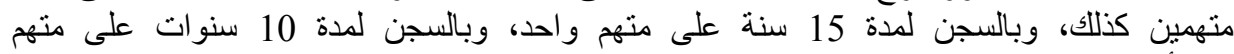

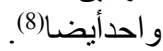

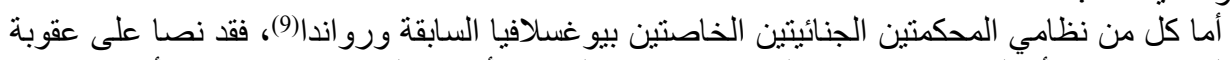

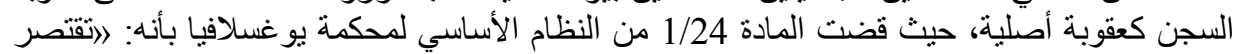

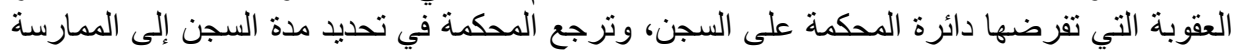

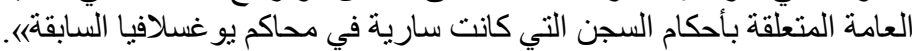

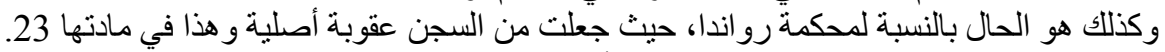

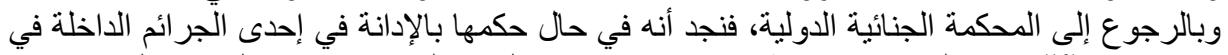

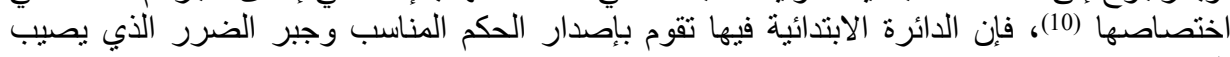

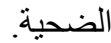
و العقوبات الأصلية التي يجوز للائرة الابتدائية أن تصدر ها هي نلك الواردة بادية بالمادة 77 من النظام

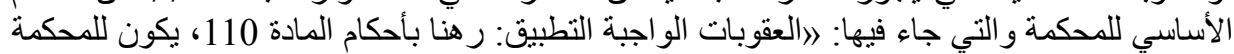

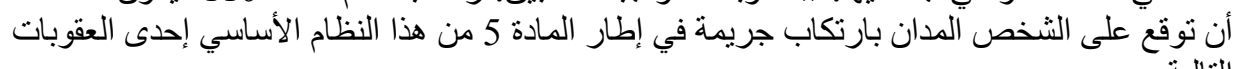

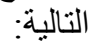
ـالسجن لعدد محدد من السنوات لفترة أقصاها 30 سنة. ـالسجن المؤبد حيثما تكون هذه العقوبة مبررة بالخطورة التهنة البالغة للجريمة وبالظروف الخاصة للثخص

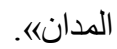

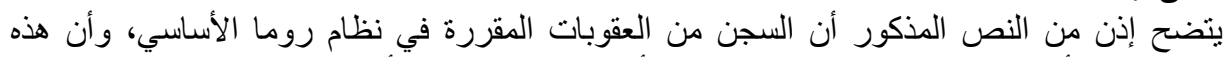

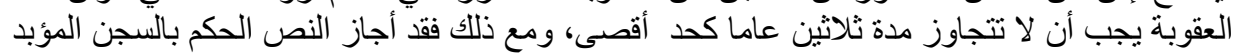

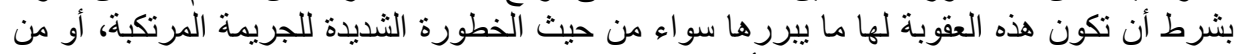

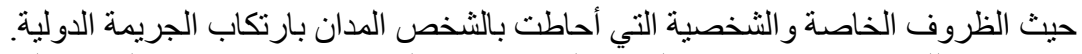

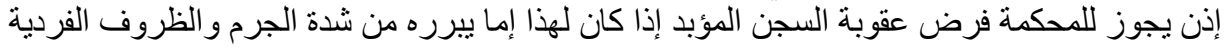
اللثخص المدان(11).

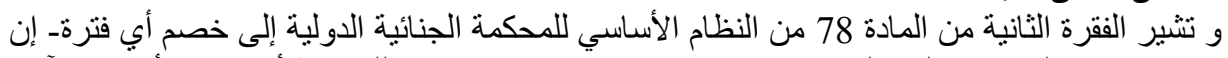

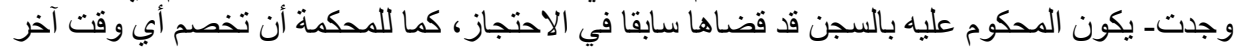

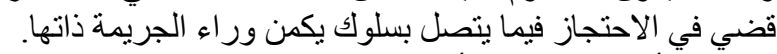

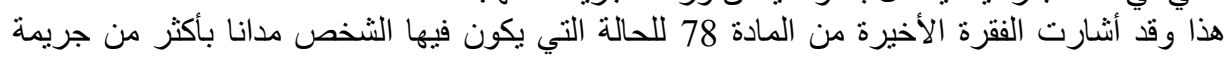

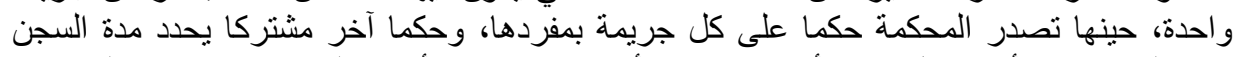

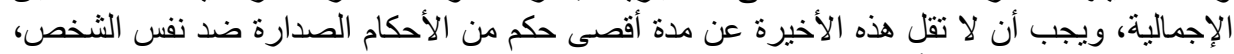

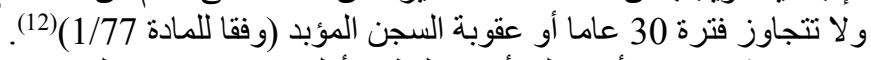

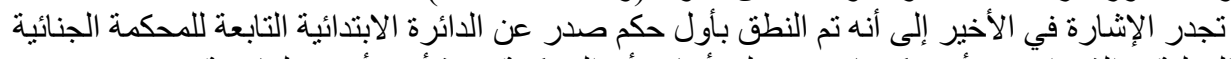

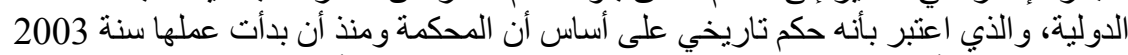

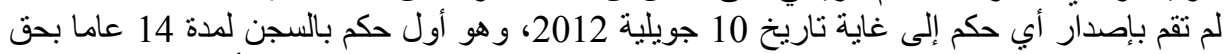

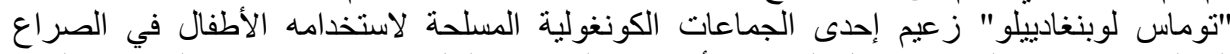

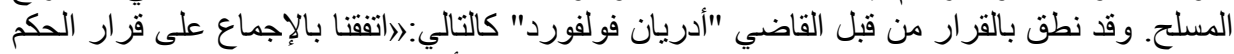

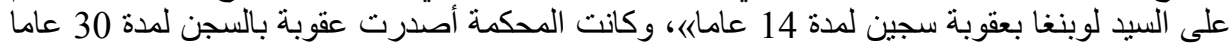

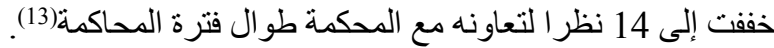

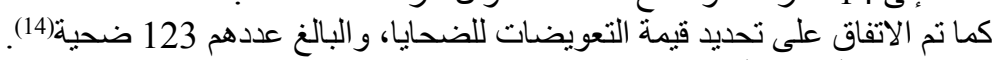
ثانيا: العقوبة السالبة للحياة (الإعدام) تعد عقوبة الإعدام من أقدم العقوبات والإعام) وداً من الناحية التاريخية، فقد لجأ إليها الإنسان في بداية الوجود 


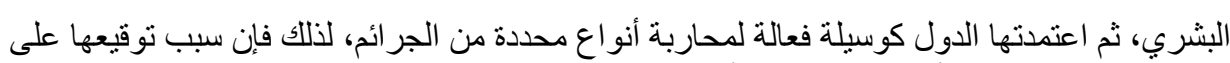

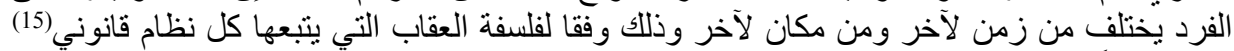

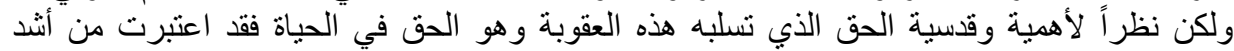

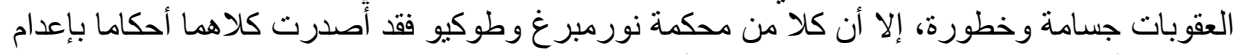

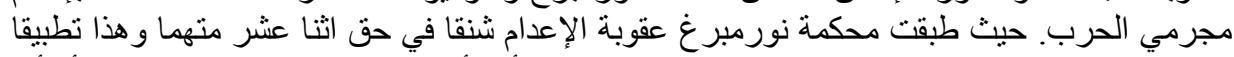

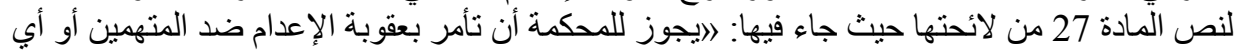

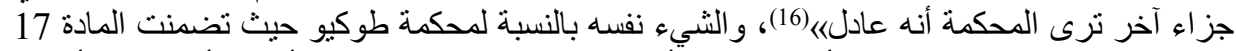

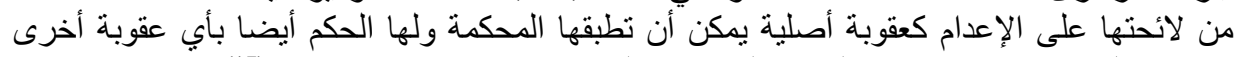

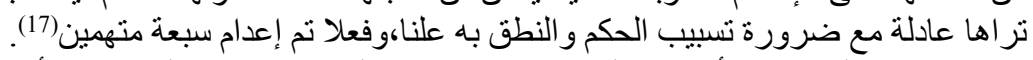

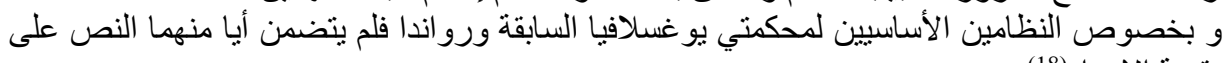

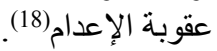
أما بالنسبة للإحكمة الجنائية الدولية، فعند مناقثة ممثلي الدول في اللجنة التحضيرية، انقسم المؤتمرون

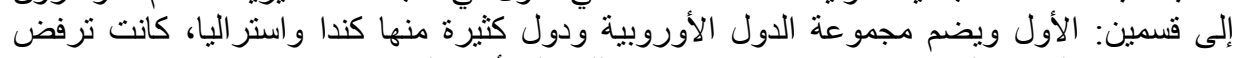

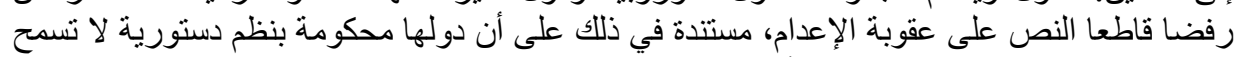

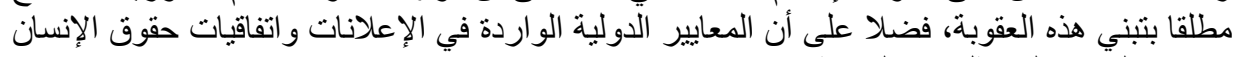
تناهض النص على مثل هذه العقوبة.

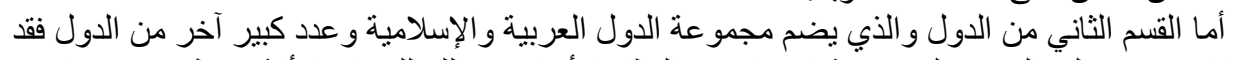

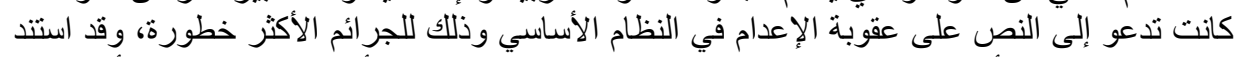

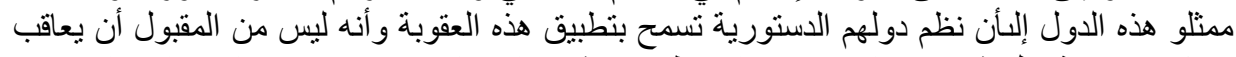

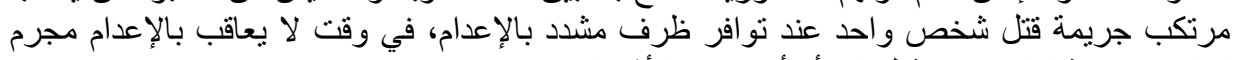
ارتكب جريمة إبادة جماعية لمئات أو ألاف من الأشخاص.

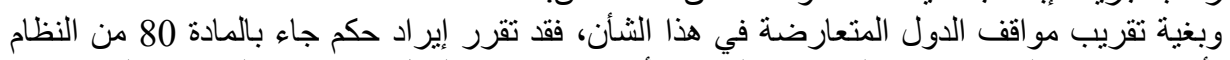

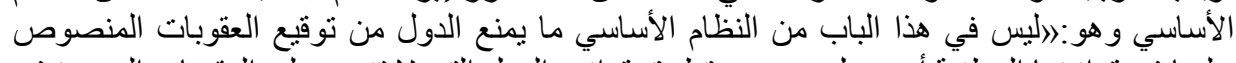

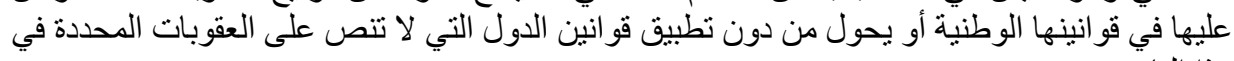

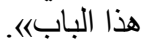

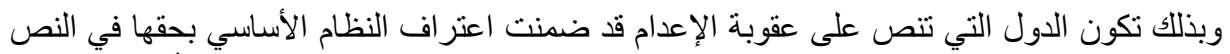
على هذه العقوبة والإبقاء عليها إذا مارست الاختصاص الإن القضائي الوطني وكانت قد أدرجت عقوبة الإنة الإعدام في قو انينها الداخلية(19).

الفرع الثاني: العقوبات التبعية (المالية)

ألعقوبات المالية هي تلك التي تصيب التئية الذّة المالية للمحكوم عليه، وتتمثل في الغر امة و المصادرة.

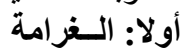
تعد الغرامة من أقدم العقوبات وترجع في أساسها إلى نظام الدية الذي كان مطبقا في الشرائع القديمة

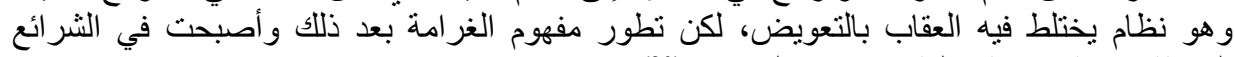

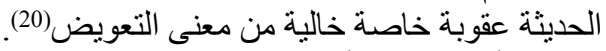

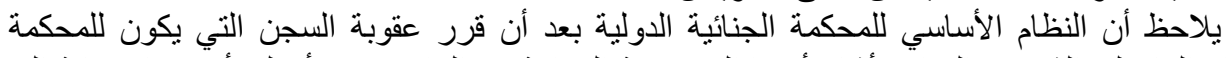

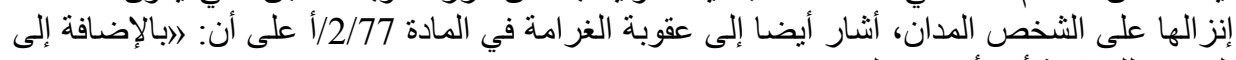

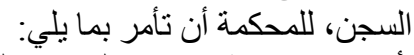

أ_فرض غرامة بموجب المعايير المنصوص عليها في القو اعد الإجر ائية وقو اعد الإثبات). حيث حددت

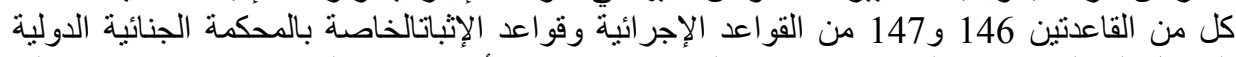

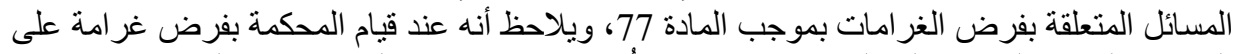

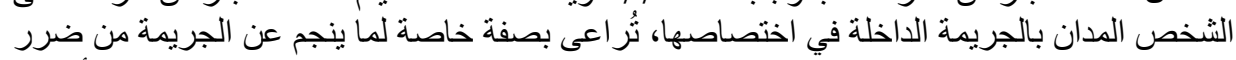

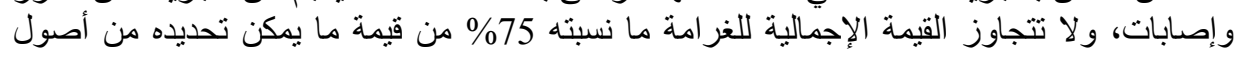


سائلة أو قابلة للتصريف و أمو ال يملكها الثخص المدان، بعد خصم مبلغ مناسب يفي بالاحتباجات المالية

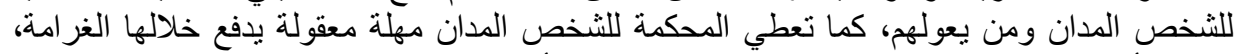

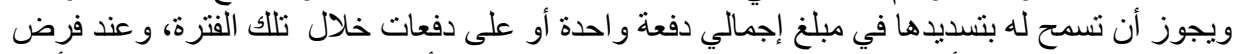

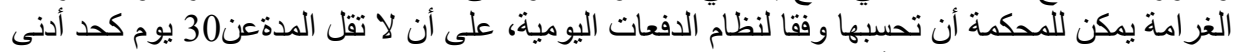

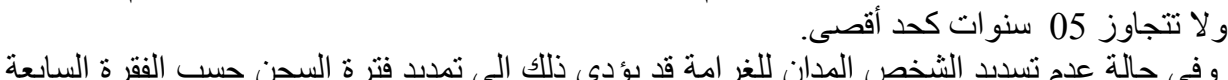

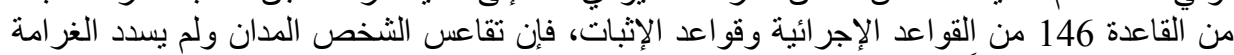

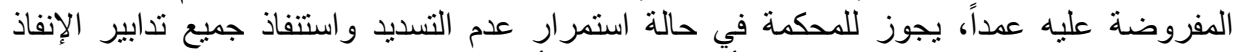

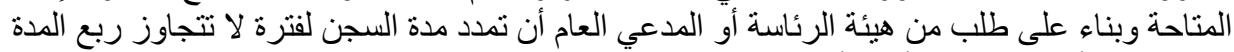

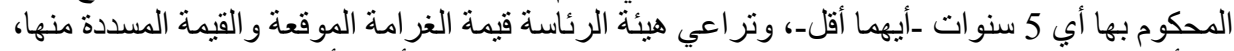

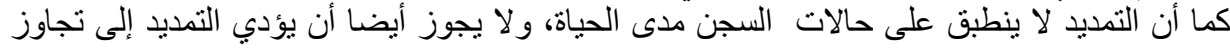

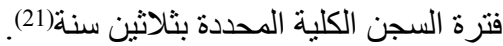
ثانيا: المصادرة

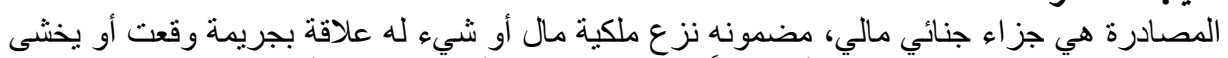

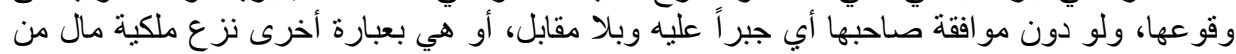

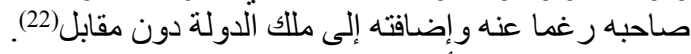

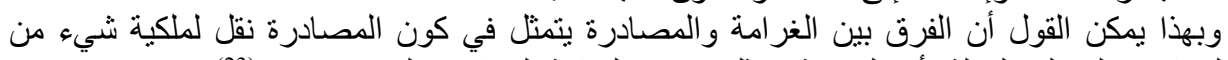

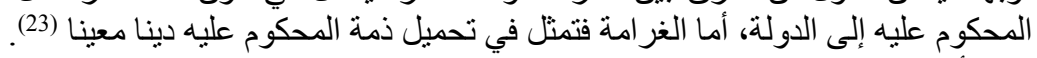

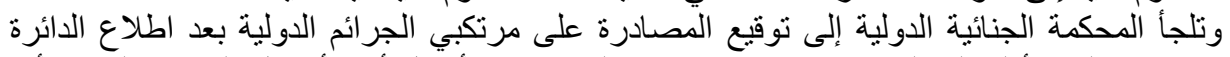

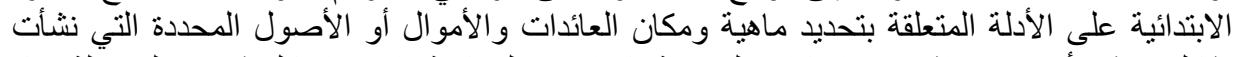

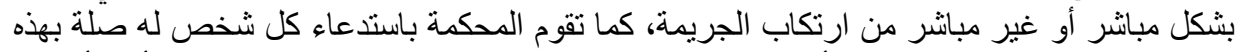

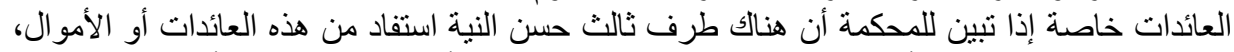

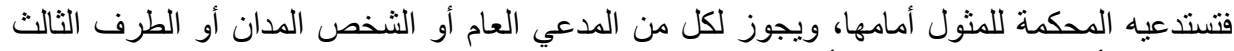

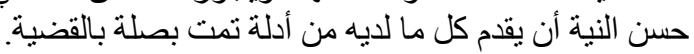

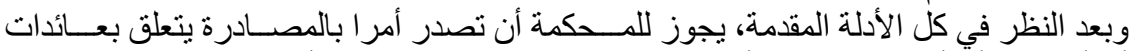

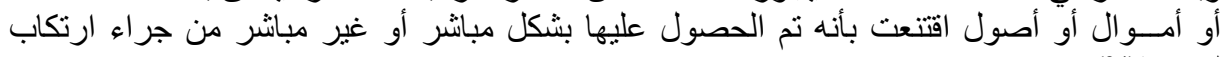

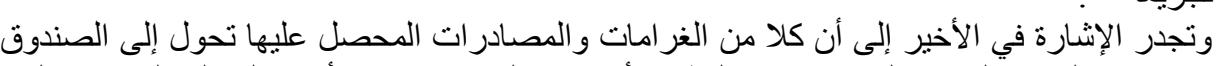

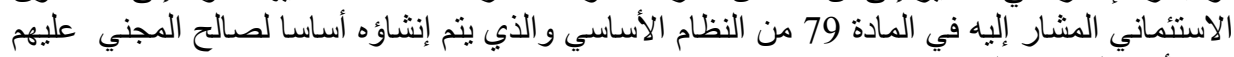

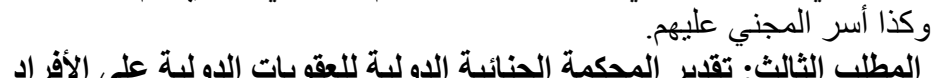

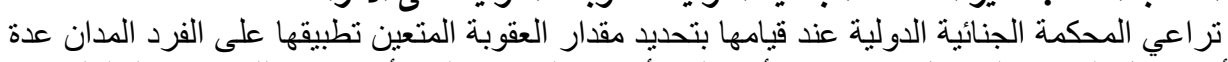

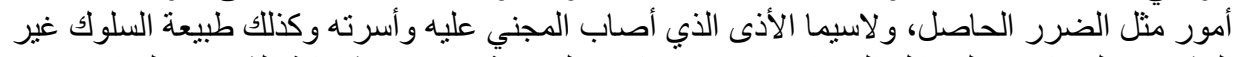

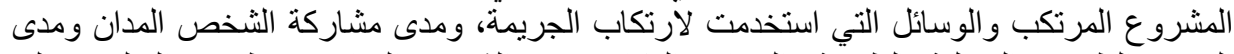

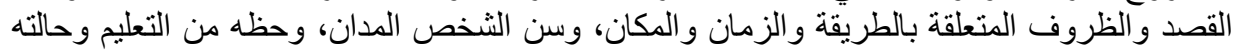

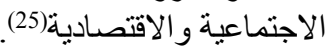

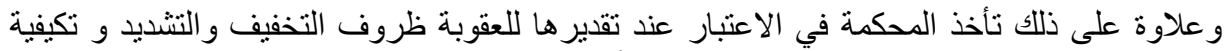

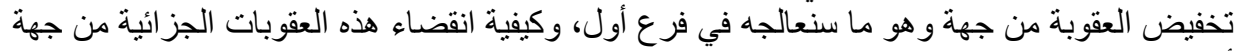

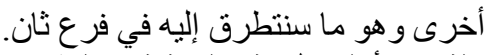

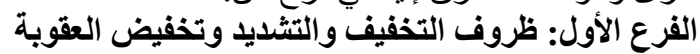

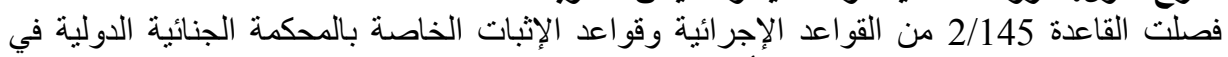

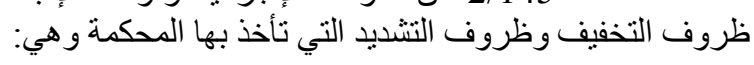


أولا: ظروف التخفيف وظروف التثديد:

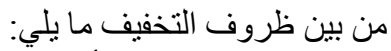

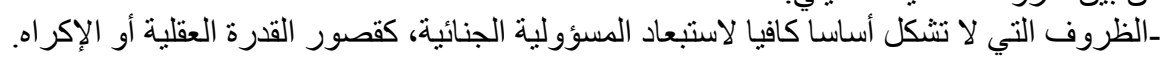

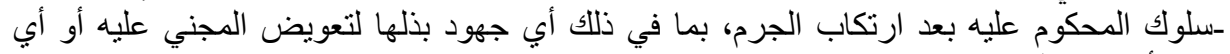

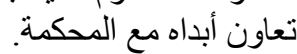

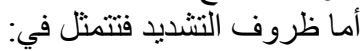

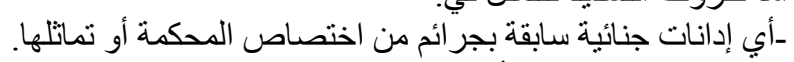
- إسباءة استعمال السلطة أو الصفة الرئة الرسمية.

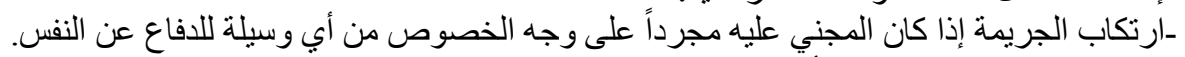

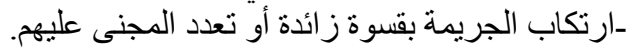
ـارتكاب الجريمة بدافع ينطوي على التمييز وفــابل لأي من الأسس المشار إليها في الفقرة 3 مـن المادة

ـأي ظروف لم تذكر ولكنها تعد بحكم طبيعتها مماثلة لتلاك المذكورة أعلاه.

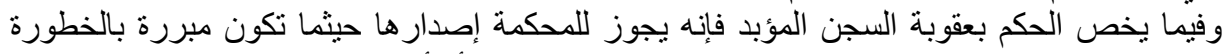

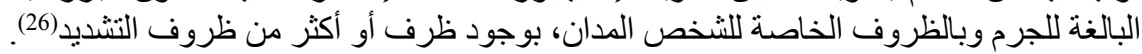

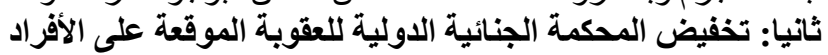

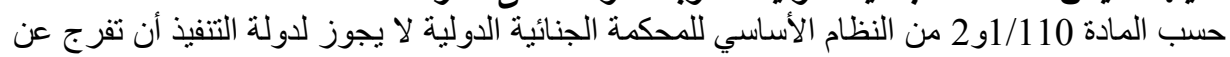

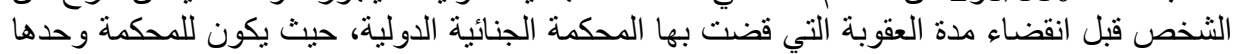

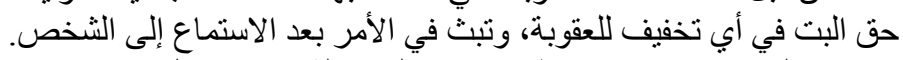

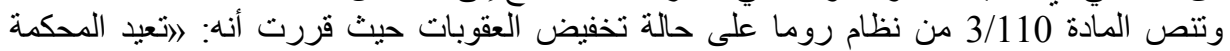

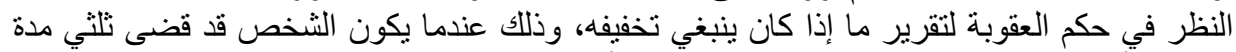

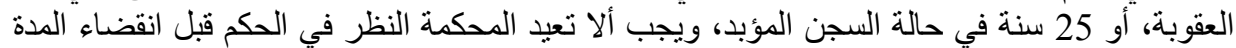

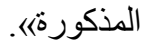

و الجدير بالذكر أنه إذا كان للدحكة الجنائية الدولية سلطة إعادة النظر في مسألة تخفيض العقوبةإلا أنه

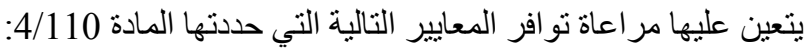

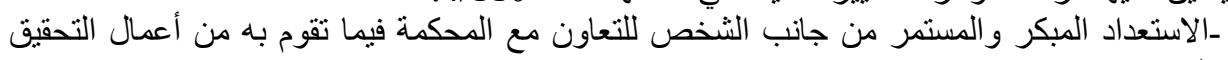

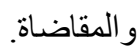

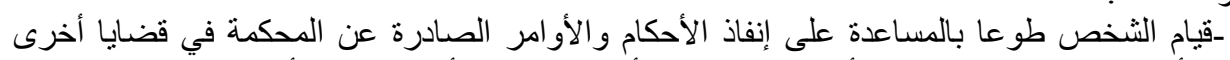

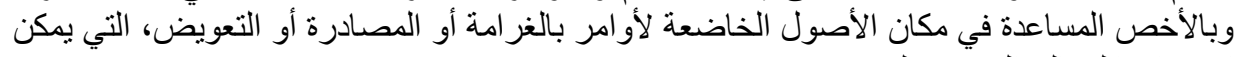
استخدامها لصالح المجني عليهم. وقد تضدنت القاعدة 223 من القو اعد الإجر ائية وقو اعد الإثبات الخاصة بالئن بالمكمة الجنائية الدولية عدة

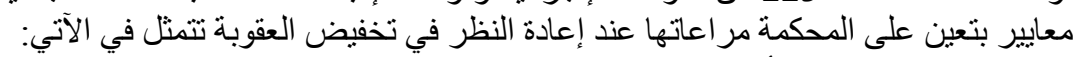

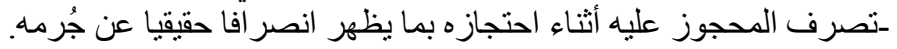

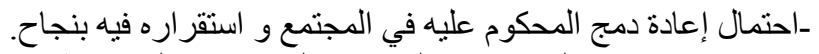

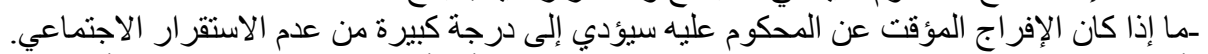

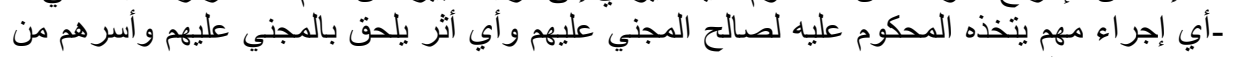

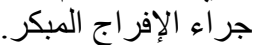

ـالظروف الثخصية للمحكوم عليه، بما في ذللك تدهور حالته البدنية أو العقلية أو تقدمه في السن.

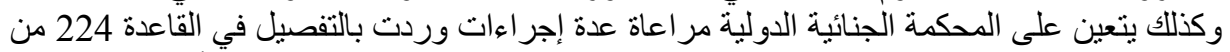

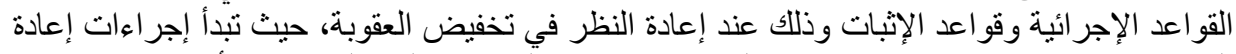

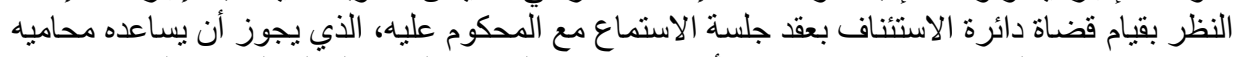
مع توفير ما قد يلزم من ترجمة شفوية، و أيضا بحضور الاسنياع الددعي العام والدولة القائمة بالتنفيذ، وتدعو 
أيضا إلى الحد المستطاع المجني عليهم أو ممثليهم القانونيين الذين شاركو ا في الجلسة الأولى.

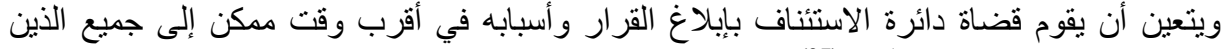

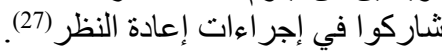

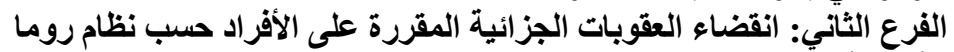

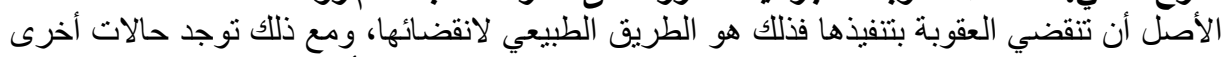

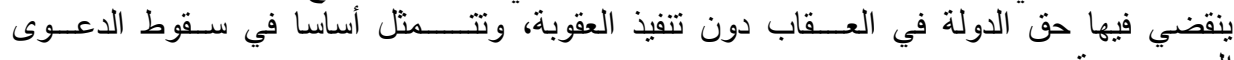
أو سقوطُ الحكم بالتقادم، وفاة المحكوم عليه أو العفو عن العقوبة.

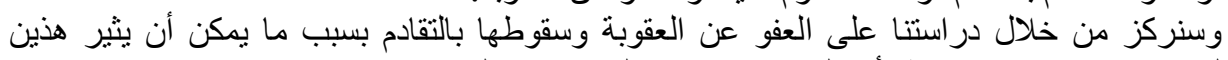
السببين من إثكالات قانونية، أما الوفاة فهي تؤدي إلى انقضاء الدوني الدعوى فور ا. أولا: العفو عن العقوبة العانية

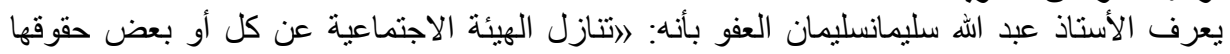

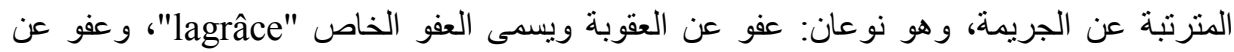

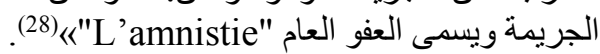

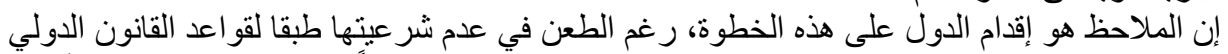

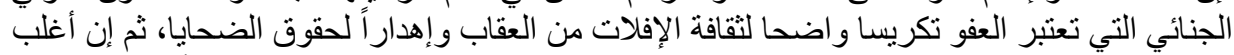

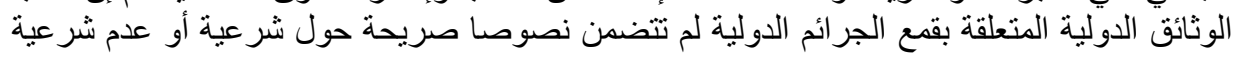

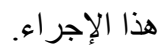

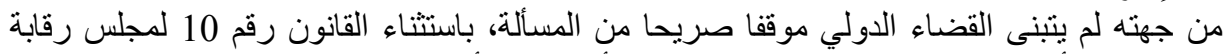

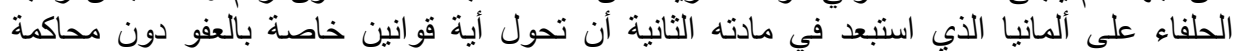

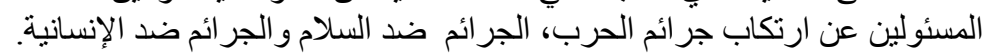

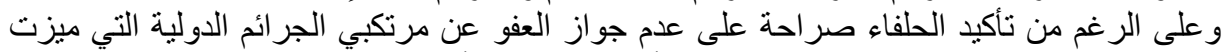

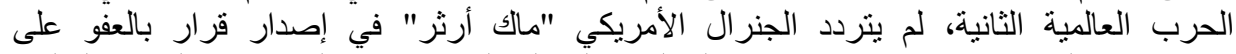

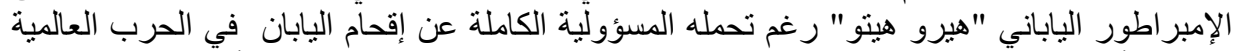

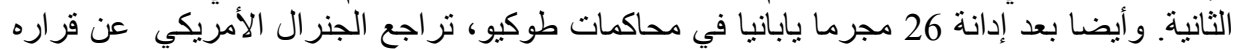

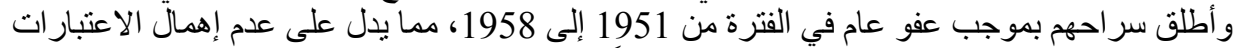

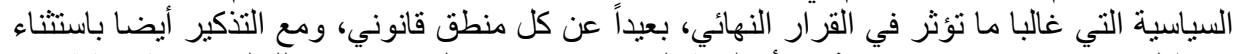

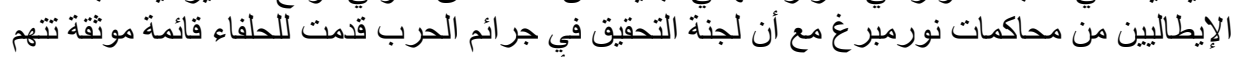

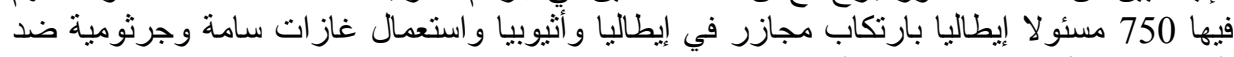

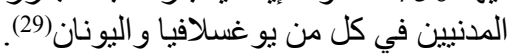

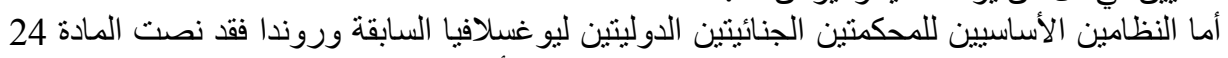

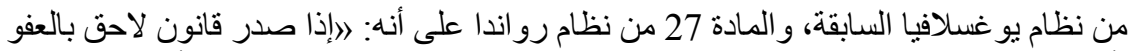

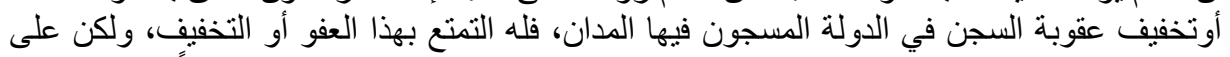

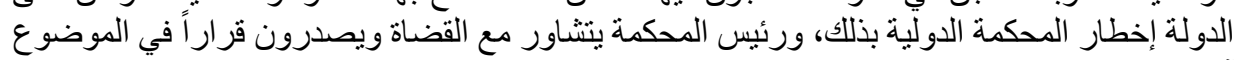
آخذين في الاعتبار تحقيق مصلحة العدالة العالة والمبادئ العامة للقانونهان.

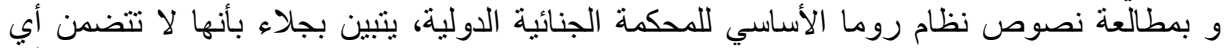

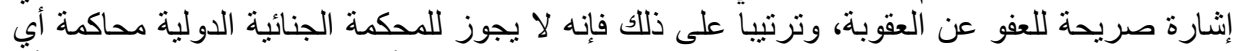

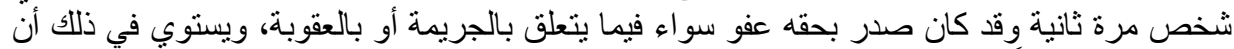
يكون العفو صادراً من البرلمان أو رئيس الجمهورية.

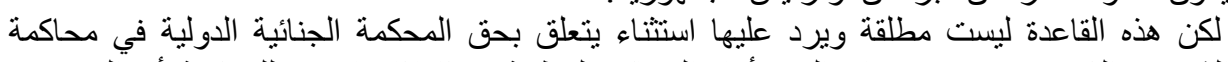

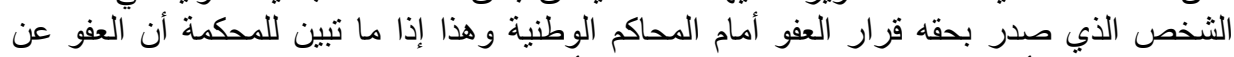

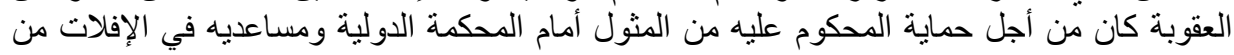


ومن جهة أخرى تتص المادة 110 في فقرتيها 1 و2 على أنه: 》الا يجوز لدولة التنفيذ أن تفرج عن الثخص قبل انقضاء العقوبة التي قضت إن بها المحكمة.

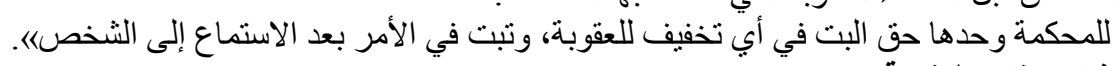
ثانيا: تقادم العقوبة.

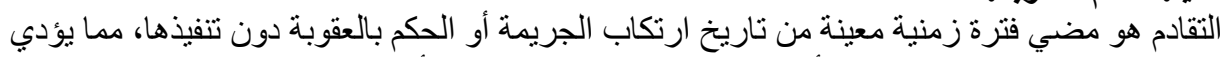

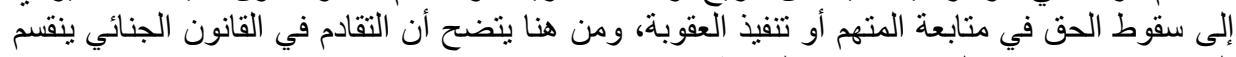

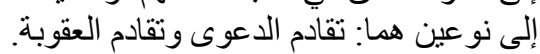

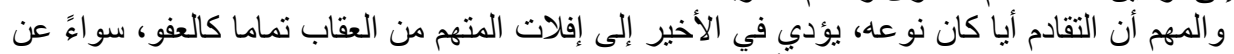

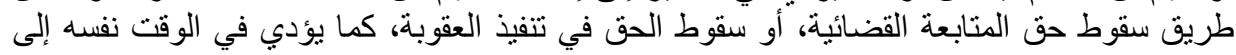

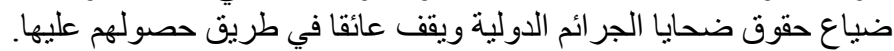

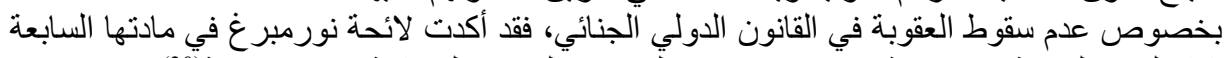

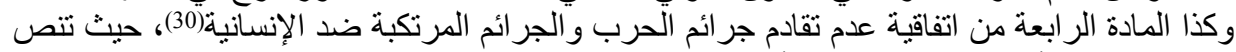

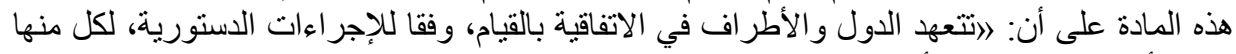

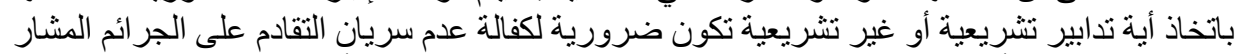

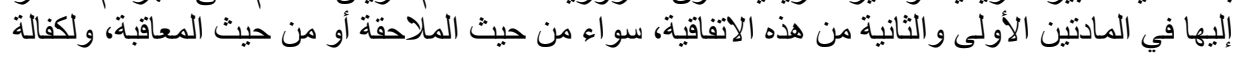

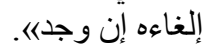

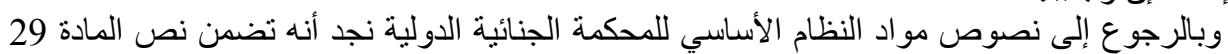

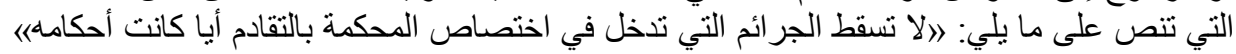

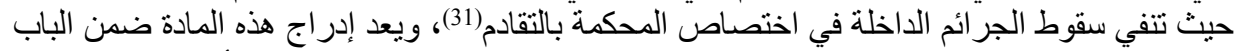

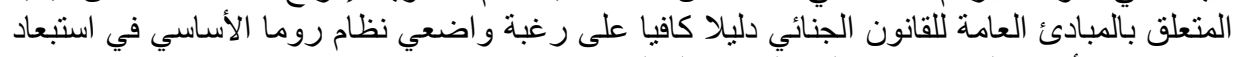

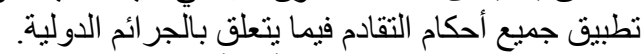

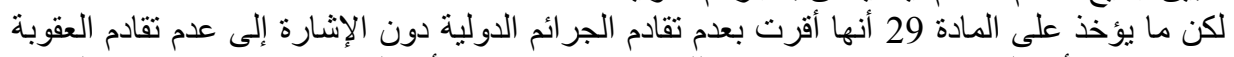

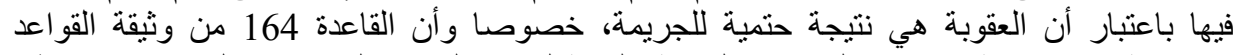

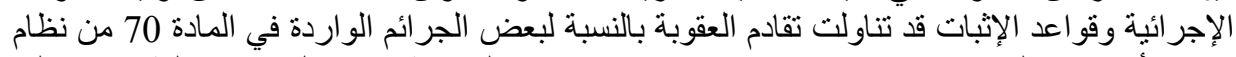

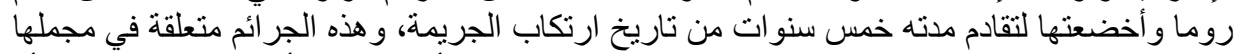

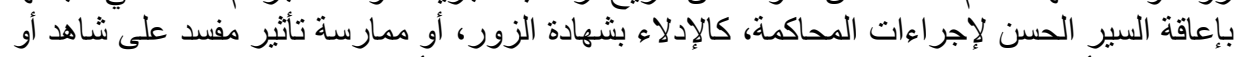

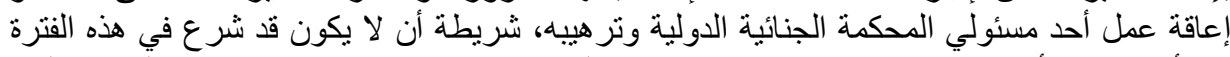

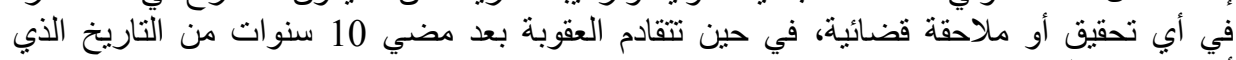
أصبحت فيه العقوبة نهائية.

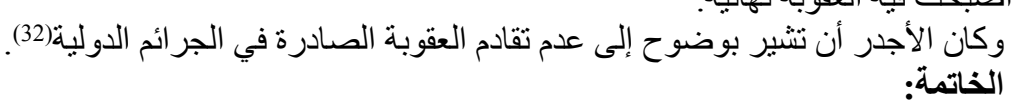

تجسدت فكرة العقاب على الجرائم الدولية بعد ويلات الحرب العالمية الثانية و التي عرفت اخطر

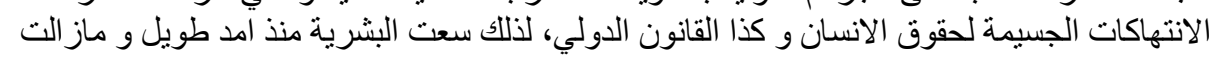

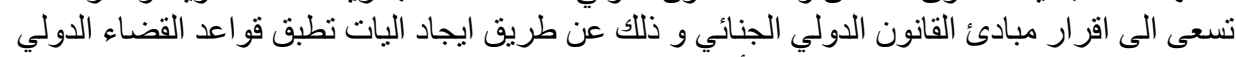

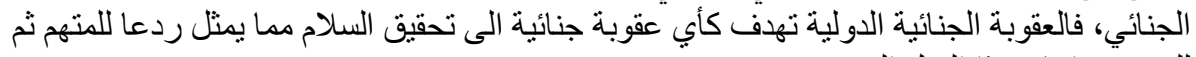

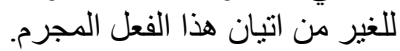

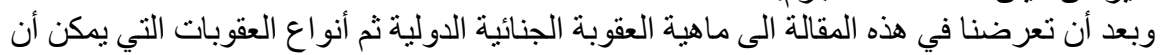

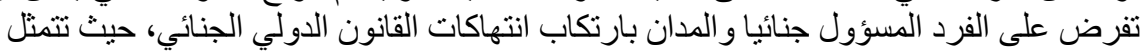

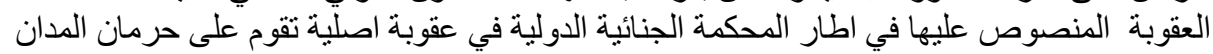

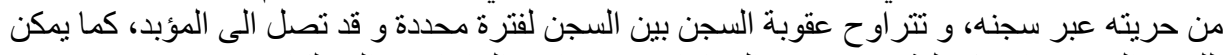

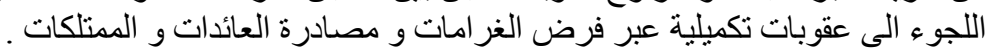




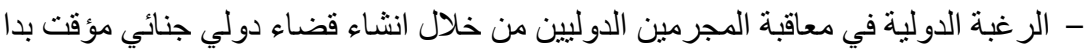

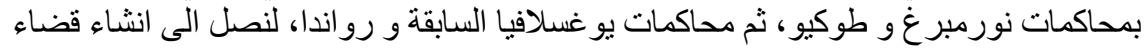

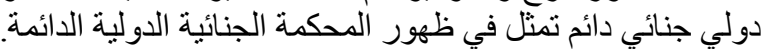

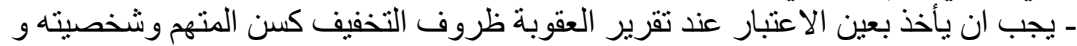

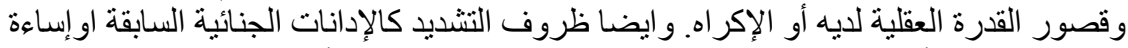

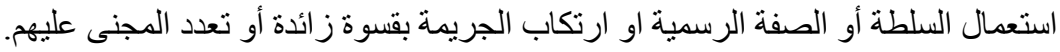

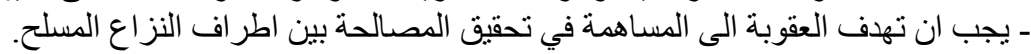

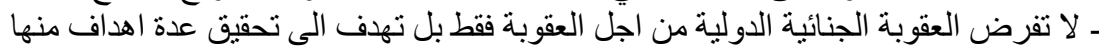

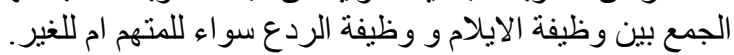

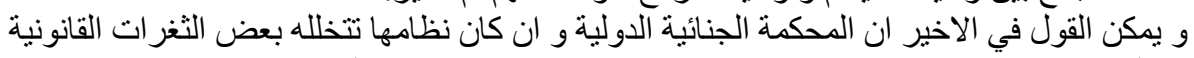

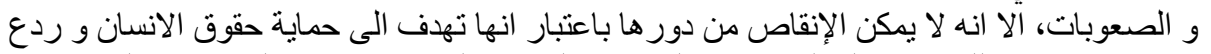

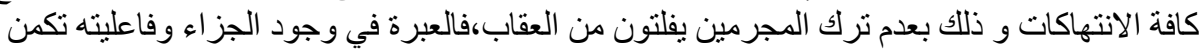

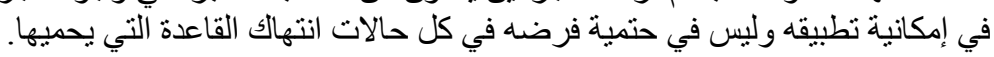

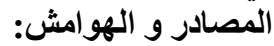

ص(1)ـ السيد ابو عطبة، الجزاءات الدولية الدولية بين النظرية و النطبيق، مؤسسة الثقافة الجامعية، مصر- 2001،

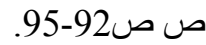

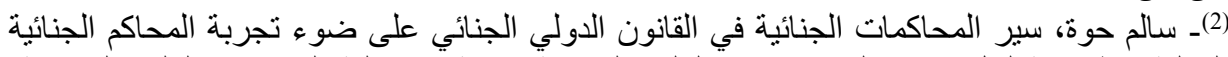
الدولية، اطروحة لنيل شهادة الدكتور اه في العلوم القانونية مقدمة أمام كلية الحقوق و العانية العلوم العانية السياسية،

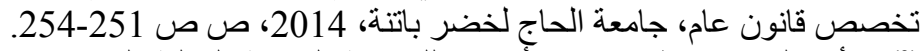

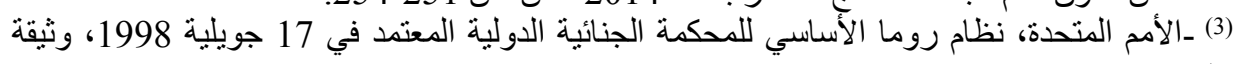
رقم: Pcn. icc/1999/inf/3 الاردن نجوى يونس سديرة،ضمانات المتهم أمام المحكمة الجنائية الدولية، الطبعة الاولى، دار الثقافة، الاردن، 2014، ص صن صديرة 292-293. (5) راجع نص المادة 74 من النظام الاساسي للمحكمة الجنائية الدولية ، و القاعدة 142 من من وثيقة

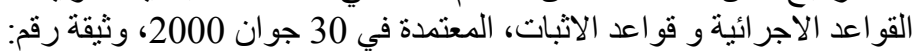
pcn.icc/2000/inf/3/add.1 (6) - ـ راجع نص المادة 32 من النظام الاساسي للمحكمة الجنائية الدولية.

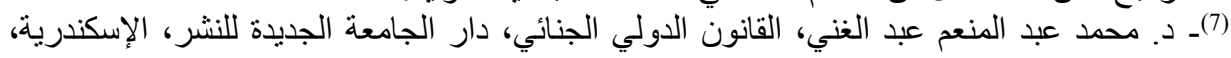

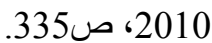
(8) ـمريم ناصري، فعالية العقاب على الانتهاكات الجسيمة للقو اعد الدولي الإنساني، دار الفكر الجامعي،

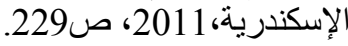

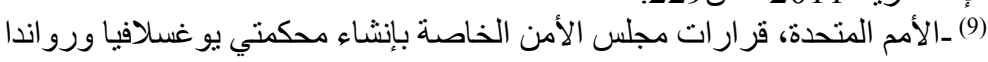

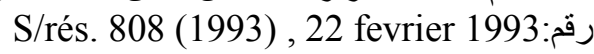
1993S/rés. 827 (1993). 25 mai 1994 S/rés. 955 (1994), 08 novembre

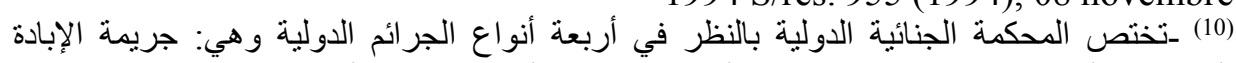

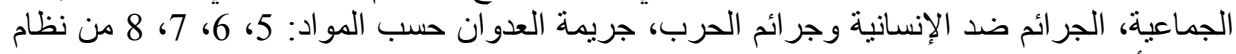

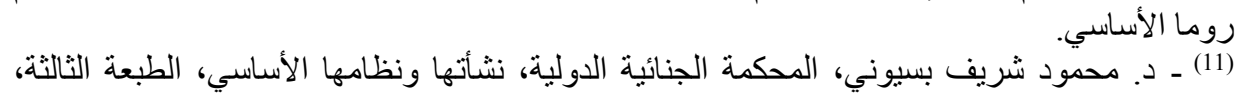

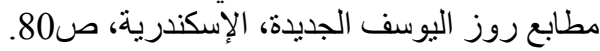
(12) ـمريم ناصري، المرجع السابق، ص232. 
(13)-situation en Répubique Démocratique du Congo,affaire, Le procureur contre Thomas LubangaDyilo, décision relative à la peine rendue en application de l'article $76 \mathrm{du}$ statut, la chambre de première instance $1 \mathrm{n}^{\circ}$ : Icc-01/04/06, date: 10 juillet 2012, la cour pénale internationale.

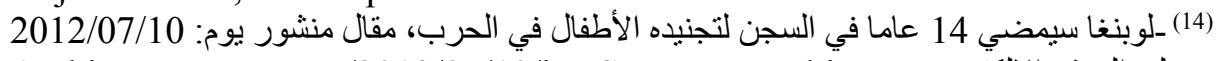
على الموقع الإلكتروني:-Arabic.euronews.com/2012/07/10/icc-Senteuces-Lubinga في في الإل For-warcrines

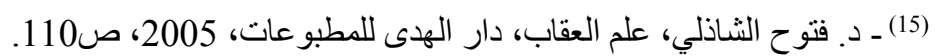

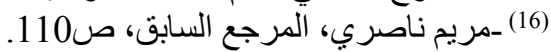

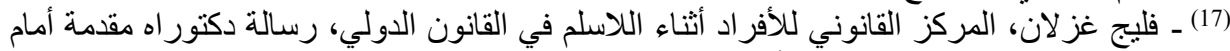

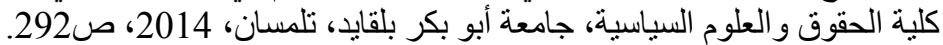

(18)_بلقيس عبد الرضا، الحماية الدولية للمدنيين خلال النزاعات المسلحة ، منشور ات الحات الحلبي الحقوقية،

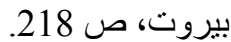

(19) - بوطبجة ريم، اجر اءات سير الدعوى امام المحكمة الجنائية الدولية، مذكرة ماجستير مقدمة امام

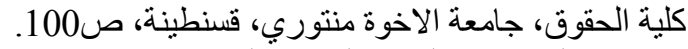

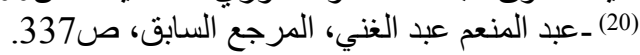

(21) ـالقاعدة 146/ 14، 2، 3، 4، 3، 5، 6، 7 3ن من القواعد الإجرائية وقو اعد الإثبات الخاصة بالدكمة

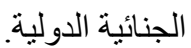

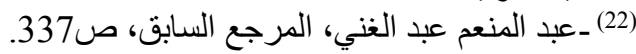

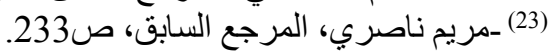

(24)ـ القاعدة 147/ 1، 2، 3، 4، من القو اعد الإجرائية وقواعد الإثبات الخاصة بالمحكمة الجنائية

لاالمكمة المادة 1/78 من نظام روما والقاعدة 1/145 من وثيقة القواعد الإجر ائية وقو اعد الإثبات الخاصة

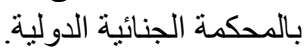

26) ـالقاعدة 145/ 2، 3 من القو اعد الإجر ائية وقو اعد الإثبات الخاصة بالمحكمة الجنائية الدولية.

(27) -Olivier De Frouville, Droit International Pénal ,sources, incriminations, responsabilité, EditiouiA.Pedone,2012,p486.

الجز (28) عبد الله سليمانسليمان، المقدمات الأساسية في القانون الدولي الجنائي، ديوان المطبو عات الجامعية،

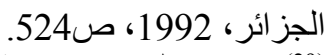

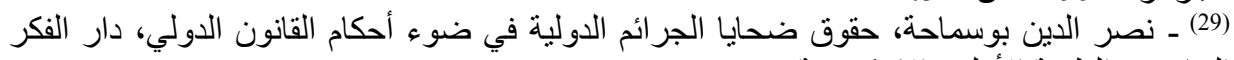

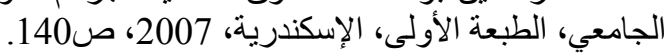

والانـعرضت اتفاقية عدم تقادم جرائم الحرب والجية والجرائم المرتكبة ضد الإنسانية للتوقيع و التصديق

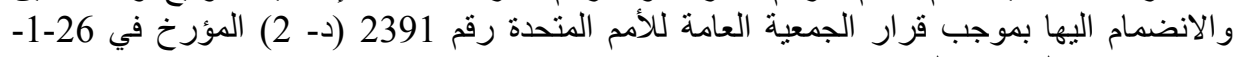

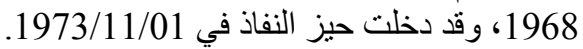

(31)-William Bourdon et Emmanuelle Du Verger, La cour pénale internationale, le statut de Rome, Edition du Seuil, Paris, Mai,2000,p125.

$$
\text { (32) ـ محمد عبد المنعم عبد الغني، المرجع السابق، ص352. }
$$

